\title{
Recerca geològica i geoambiental per les comarques del Berguedà i del Bages: Des de I'Espunyola a Casserres, Viver, Serrateix, Castelladrall i a Súria
}

Josep Maria Mata-Perelló

Joaquim Sanz Balagué

\section{XARAGALL \\ REVISTA DE CIÈNCIES DE LA CATALUNYA CENTRAL}

\section{n. 4}

ABRIL 2014 


\section{RECERCA GEOLÒGICA I GEOAMBIENTAL PER LES COMARQUES DEL BERGUEDÀ I DEL BAGES: DES DE L'ESPUNYOLA A CASSERRES, VIVER, SERRATEIX, CASTELLADRAL I A SÚRIA}

\section{JOSEP MARIA MATA-PERELLÓ}

Museu de geologia Valentí Masachs, Escola Politècnica Superior d'Enginyeria de Manresa (EPSEM), Universitat Politècnica de Catalunya · BarcelonaTech (UPC), 08272 Manresa, Spain

\section{Joaquim Sanz Balagué}

Departament d'Enginyeria Minera i Recursos Naturals (EMRN), Escola Politècnica Superior d'Enginyeria de Manresa (EPSEM), Universitat Politècnica de Catalunya - BarcelonaTech (UPC), 08272 Manresa, Spain

Paraules clau: Depressió geològica de l'Ebre; Cenozoic; explotacions mineres, patrimoni miner

\section{Resum}

Itineriari realitzat el 23 de març del 2013. En aquesta ocasió, el recorregut del present l'itinerari discorrerà, en la seva practica totalitat per la Depressió Geològica de l'Ebre, tot i que molt prop del Pirinenc, pels trams inicials (pels voltants de l'Espunyola). Més endavant, la totalitat del recorregut de l'itinerari es desenvoluparà estrictament per l'esmentada depressió.

Així, en els primers trams es circularà per la denominada Depressió Geològica de l'Ebre; i més concretament, als trams finals per la seva Depressió Central, especialment entre I'Espunyola i Súria, al llarg de tot el recorregut de l'itinerari.

Per d'altra banda, el recorregut transitarà per dues de les comarques que formen part de la Catalunya Central, la del Berguedà i la del Bages. Així, el recorregut començarà a l'Espunyola, per on es circularà dintre de la comarca fins arribar a Serrateix. A partir d'aquí, s'entrarà a la comarca del Bages, per on es circularà des de Castelladral fins arribar a la població de Súria, per on finalitzarà el recorregut. 


\section{Objectius fonamentals d’aquest itinerari}

Els objectius fonamentals que es pretenen aconseguir en aquest itinerari geològic i geoambiental, són els següents:

1. Observació dels afloraments de la Depressió Geològica de l’Ebre, per la qual es circularà entre l'Espunyola i el fi del recorregut. Tot i que els primers trams es situen dintre de I'Avant-País Plegat.

2. Observació dels afloraments dels materials cenozoics que formen part de la Depressió Geològica de I’Ebre (i tanmateix de la Zona de I'Avant-País Plegat). Aquests materials els tallarem al llarg de tot el recorregut de l'itinerari. Fonamentalment, es tracta dels materials del de la Formació Solsona (amb gresos i calcolutites ocres) i dels de la Formació Artés (amb gresos i calcolutites rojes).

3. Estudi i descripció de diferents mineralitzacions, i també de les explotacions situades al llarg del recorregut.

4. Observació de les explotacions mineres (antigues i actuals), relacionades amb les mineralitzacions anteriors. I alhora, observació de l'impacte sobre el Medi Natural, produït per les explotacions anteriors; i si s'escau de les restauracions dutes a terme per tal d’eliminar-lo.

5. Observació dels diferents indrets relacionats amb el patrimoni geològic i amb el patrimoni miner, que es vagin trobant al llarg del recorregut del present itinerari.

\section{Antecedents bibliogràfics}

En relació amb el recorregut del present itinerari, solament existeix un antecedent, concretament nostre. Es tracta de Mata - Perelló (2006) i sols fa referencia a la part final del recorregut. Així, el present constitueix una primícia.

Per d'altra banda, en canvi, farem esment de diversos treballs, de caràcter geològic general i regional, com són els següents: Guimerà et altri (1992), i Riba et altri (1976). Igualment, es pot fer esment de les recents publicacions de l’IGME (1994a i 1994b).

I, pel que fa a l'estudi de les mineralitzacions situades dintre de l'àrea per la qual discorre l'itinerari, farem esment d'un altre treball nostre, concretament del Mata-Perelló (1991). També, en treball més monogràfic, es poden trobar antecedents a Mata-Perelló (1984) i al treball de Mata-Perelló i Sanz Balagué (1991).

Tots aquests treballs, i d'altres, figuraran degudament relacionats per ordre alfabètic, i per data de publicació, dintre de l'apartat d'aquest treball dedicat a les referències bibliogràfiques, al qual ens remetem.

\section{Descripció del recorregut de l’itinerari}

El recorregut del present itinerari, śiniciarà a la localitat de l’Espunyola, per on es realitzarà la primera aturada d'aquest itinerari. Des d'aquí, es continuarà breument per la carretera autonòmica $C-26$. Poc després de sobrepassar l'Espunyola. Es continuarà per la carretera 
local BV - 4131. En arribar a Casserres, ens caldrà seguir per una carretera local que es dirigeix cap a Viver. En aquest tram s'efectuaran diverses aturades.

Després, es seguirà cap a Serrateix, per la carretera local BV - 4235. En aquest tram, $s^{\prime}$ efectuaran diverses aturades. Tot seguit, el recorregut continuarà per una carretera local cap al poblet de Castelladral. Posteriorment, des d'aquest poble s'anirà cap a Súria, tot seguint ara la carretera local $\mathrm{B}-423$. Finalment, en arribar a Súria finalitzarà el recorregut d'aquest itinerari, realitzant-se les darreres aturades.

\section{Advertiment previ}

Com en altres recorreguts de RECERCA GEOLÒGICA I MINERALÒGICA ..., si es disposa del temps suficient, poden efectuar-se passant per totes les parades i filloles. En cas contrari, recomanem prescindir de les anomenades PARADES - CONDICIONALS.

També recomanem de cercar la informació més adient, sobre els trams a recórrer mitjançant camins de terra, o de pista.

Per d'altra banda, recomanem tenir una cura extrema de la NATURA, evitant qualsevol forma d'agressió sobre ella, o de fer-n'hi un mal ús del que en ofereix la nostra mare Terra.

\section{Descripció de l'ítinerari}

En aquest recorregut hem situat, com ja és habitual en tots els altres itineraris de recerca, una sèrie d'estacions o de parades, que anirem veient a continuació. En cada cas, els hi donarem una denominació que podrà correspondre a algun paratge proper.

Per d'altra banda, en cadascuna de les parades, indicarem entre parèntesi el número del "Mapa Topográfico" del "Instituto Geográfico y Catastral de España", a escala 1:50.000, on es troba situada la parada considerada. En aquesta ocasió, utilitzarem els següents fulls topogràfics: 292 (o de Sant Llorenç de Morunys), 293 (o de Berga), 330 (o de Cardona) i 331 (o de Navàs).

Així doncs, la relació de les aturades que composen el recorregut del present itinerari, és la següent:

\subsection{Parada 1. Immediacions de l'ajuntament de I’Espunyola, (terme municipal de I’Espunyola, comarca del Berguedà). (Full 292).}

El recorregut de l'itinerari, el començarem en aquest indret situat quasi als costat de I'Ajuntament de l'Espunyola, a la vora de la carretera autonòmica C - 26 (tram entre Solsona i Berga), al cantó septentrional de la mateixa.

Aquest indret es troba situat a la Depressió Geològica de l'Ebre, tot i que molt prop del seu contacte amb el Sistema Pirinenc. De fet, cap el Nord mateix del poble ja es troben els relleus de I'Avant-País Plegat. Pel que fa al poble, ja es situa totalment dintre de la Depressió Central de I'esmentada Depressió Geològica de l'Ebre. 
Així, els materials que constitueixen el subsòl dels voltants de l'Espunyola, són fonamentalment els nivells de les calcolutites i gresos de la Formació Solsona. Aquests son els materials que afloren per l'indret de la present aturada. Aquests materials són cenozoics i pertanyen a I'Oligocè.

Per d'altra banda, per sobre d'on som ara, cap el Nord, apareixen uns afloraments de materials detrítics, també oligocènics. Aquests materials pertanyen al Complex Al/luvial de Berga. Així, des d'on ara som, mirant cap el Nord i cap el NE, es poden veure els relleus de la coneguda "cuesta de Capolat", amb afloraments d'aquests conglomerats. (fotografia 1).

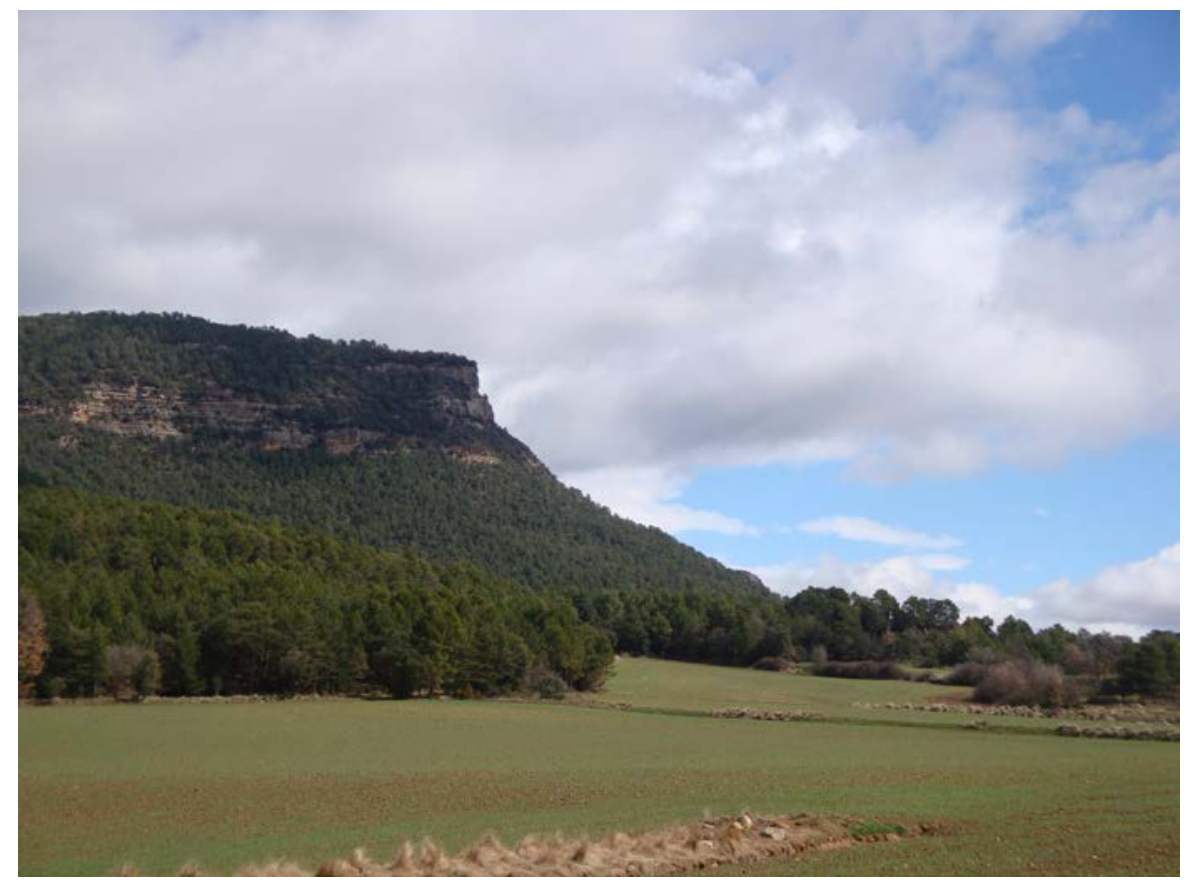

Fotografia 1. Relleus de "cuesta de Capolat", per sobre de l'Espunyola. Afloraments dels conglomerats del Complex Al.luvial de Berga

\subsection{Parada 2. Immediacions de Casserres, carretera a Viver, (terme municipal de Casserres, comarca del Berguedà). (Full 293).}

Després de fer la parada anterior, ens cal sortir de l'indret on hi ha l'Ajuntament de I'Espunyola, primer per la carretera autonòmica C - 26, (anant en el seu sentit cap a Berga) i ben aviat per la carretera local B - 4131 (la qual es dirigeix cap a Casserres i cap a Puig-reig). Així, seguint per aquesta carretera en sentit SE, aviat trobarem el trencall que es dirigeix cap al poble de Montclar (per la dreta de la marxa). Més endavant trobarem el trencall de l'Esglesiola (també per la dreta). Finalment, arribarem al poble de Casserres. Des d'aquí, del bell mig del poble, ens caldrà sortir pel camí veïnal asfaltat que condueix cap a Viver. Poc després de sortir de Casserres, podem fer una nova aturada, si s'escau. Així, des de l'anterior, haurem efectuat un recorregut proper als $9 \mathrm{Km}$ i escaig, per tal d’arribar fins aquí.

Bona part d'aquest recorregut, l'haurem efectuat entre els afloraments dels materials continentals, de tonalitats ocres de la Formació Solsona. Es tracta de nivells de gresos i de calcolutites, amb freqüents paleocanals. Aquests materials pertanyen a l'Oligocè i reblen la 
Depressió Geològica de l'Ebre, per on estem situats. Tanmateix, haurem trobat afloraments de nivells de conglomerats, en alguns trams del recorregut, que pertanyen en part al Complex Al.luvial Mitjà de Berga. Aquests materials fan força palesos a Montclar, una mica al Sud de la ruta que hem anat seguint. (fotografia 2).

Per d'altra banda, al llarg de part del recorregut, hem circulat al Sud dels relleus tabulars de la "cuesta" de Capolat, tot i que poc a poc ens hem distanciant. Aquests relleus estan constituïts pels materials detrítics del Complex Al-luvial de Berga, amb un predomini dels conglomerats postorogènics. Com els anteriors tenen edat oligocènica.

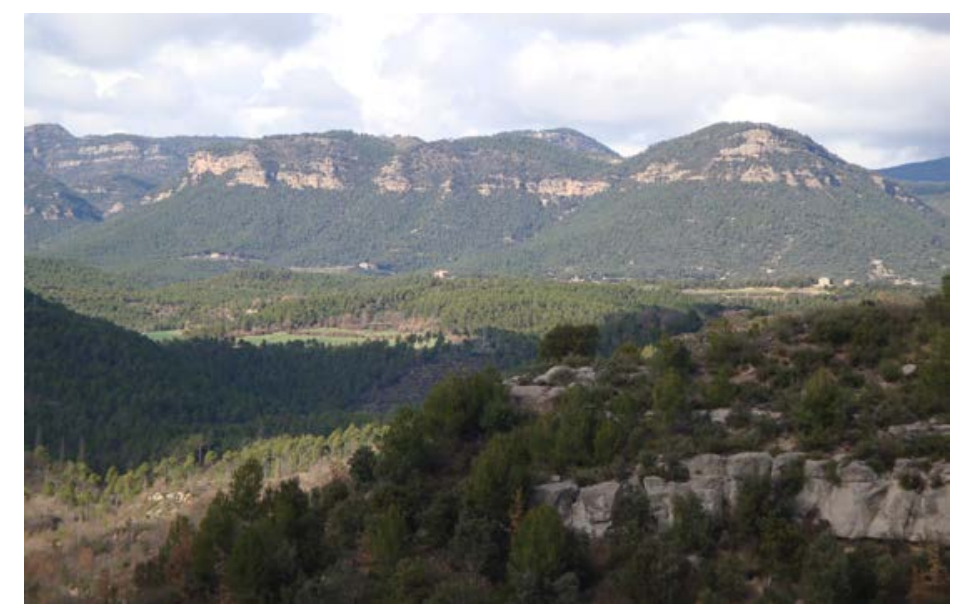

Fotografia 2. En primer terme els materials detrítics dels voltants Montclar. Cap a la part central els indrets ocupats pels gresos i calcolutites de la Formació Solsona, i al fons la "cuesta" de Capolat, amb nivells detrítics.

Des d'aquest indret, situat a poca distància de Casserres, es pot gaudir d'un bon lloc d'observació de la depressió. Fins i tot es poden veure els relleus de Montserrat en la llunyania d'on ara som. (fotografia 3).

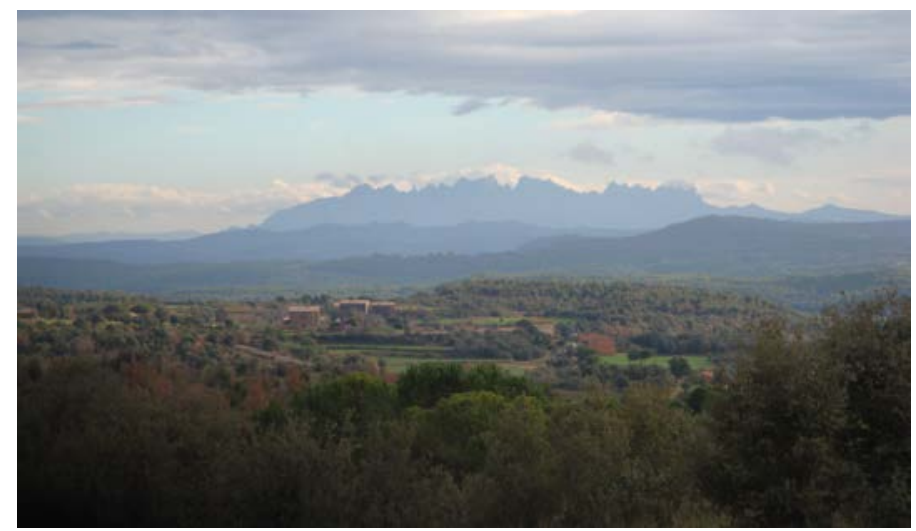

Fotografia 3. Relleu de la Depressió Geològica de l'Ebre, amb Montserrat al fons, des de Casserres 


\subsection{Parada 3 - Condicional. Immediacions de Cal Gemic, carretera a Viver, (terme municipal de Casserres, comarca del Berguedà). (Full 330).}

Després de fer la parada anterior, cal continuar pel camí veïnal (carretera) que es dirigeix cap a Viver. A uns $3 \mathrm{Km}$ i escaig, de la parada anterior, si s'escau, en podem realitzar una altra, prop del trencall de Can Gemic.

En aquest recorregut, hem continuat trobant els materials de la Formació Solsona esmentats al tram anterior. Així, haurem vist afloraments dels nivells continentals de calcolutites ocres i de gresos.

Per d'altra banda, des d'aquest indret, es pot gaudir d'una bona vista dels relleus pirinencs, situats al Nord d'on ara som.

\subsection{Parada 4. Immediacions de Can Canadal, carretera a Viver, (terme municipal de Casserres, comarca del Berguedà). (Full 330).}

Poc després de realitzar l'aturada anterior, ens caldrà efectuar un nou recorregut cap a Viver, pel camí veïnal (carretera) que hi condueix. Per les immediacions de Can Canadal, efectuarem una nova aturada.

En aquest recorregut, hem continuat trobant afloraments dels materials de la Formació Solsona, amb trams de calcolutites ocres i de gresos. Sovint, entre aquests materials es fan palesos els paleocanals, com a l'indret de l'aturada. (fotografia 4).

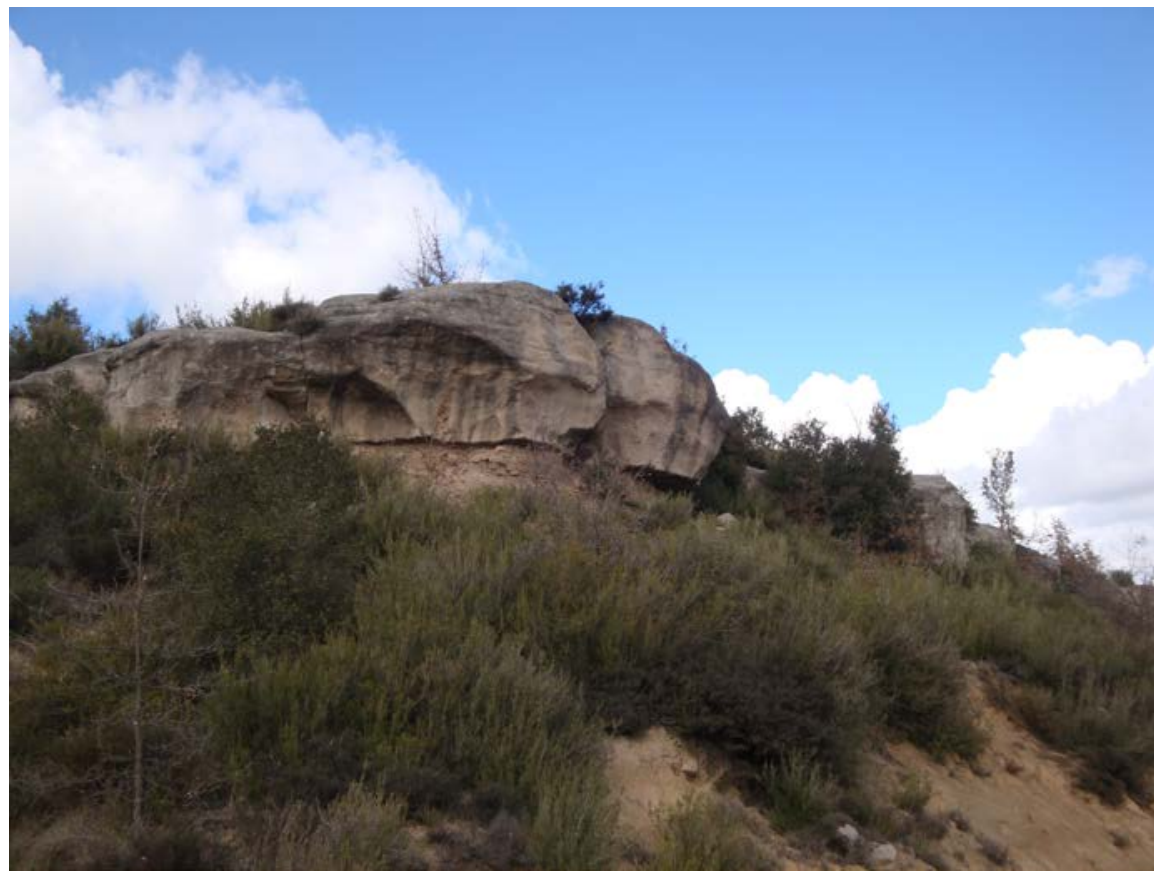

Fotografia 4. Paleocanals entre els materials de la Formació Solsona, prop de Can Canadal, Casserres 


\subsection{Parada 5. Trencall de Circuns, carretera a Viver, (terme municipal de Montmajor, comarca del Berguedà). (Full 292).}

Després de realitzar l'aturada anterior, cal continuar cap el SE, amb la intenció d'apropar-nos cap a Viver. Així, anirem circulant pel camí veïnal (carretera) que hem agafat a Casserres. En arribar al trencall de Circuns, per la dreta, efectuarem una nova aturada, a uns $2 \mathrm{Km}$ i escaig de I'anterior.

En aquest recorregut, a l'igual que en els trams anteriors, hem anat trobant afloraments dels materials continentals de la Formació Solsona, amb trams de calcolutites de tonalitats ocres alternat amb gresos. Aquests són els materials que apareixen ara a l'indret de l'aturada.

Per d'altra banda, en aquest indret, mirant cap el Nord, es pot fer una bona observació dels relleus pirinencs. (fotografia 5).

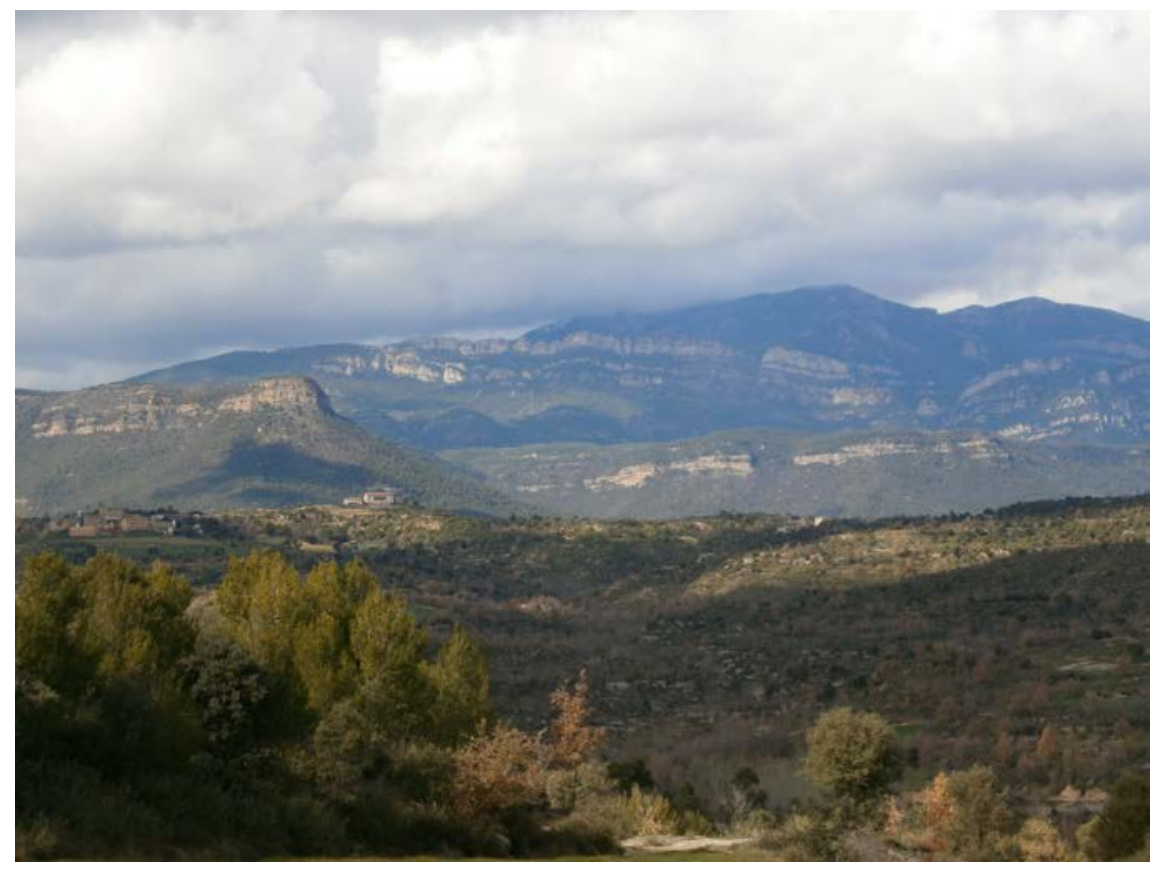

Fotografia 5. Els relleus pirinencs des del trencall de Circuns. En primer terme l'Esglesiola. A la dreta l'extrem oriental de la "cuesta" de Capolat. I al fons els relleus de Querat i dels Rasos

\subsection{Parada 6. El forn d'obra, carretera a Viver, (Sant Joan de Montdarn, terme municipal de Viver i Serrateix, comarca del Berguedà). (Full 330).}

Després de realitzar la parada anterior, cal continuar per la carretera (o camí veïnal) que condueix cap a Viver. Així, poc a poc ens anem apropant cap a Sant Joan de Montdarn. En aquest recorregut, després d'una pujada, arribarem a una teuleria ben visible, situada a la dreta de la carretera. La trobarem a uns $0^{\prime} 2 \mathrm{Km}$ de la cruillla amb la carretera procedent de Montmajor i de Montclar. En arribar al forn d'obra farem una nova aturada, aproximadament a uns $2 \mathrm{Km}$ de la realitzada anteriorment. 
En aquest recorregut, hem anat trobant els materials continentals esmentats a les aturades anteriors. Aquests materials pertanyen a la Formació Solsona i es troben constituïts per nivells de calcolutites ocres i de gresos. Tot i així, en apropar-nos a l'indret de l'aturada, harem vist intercalacions de nivells de calcolutites rogenques. Aquestes són també continentals i constitueixen un possible canvi lateral de fàcies de la Formació Solsona cap a la Formació Artés, que es troba més cap al Sud.

Per d'altra banda, en aquest indret hi ha les restes d'un antic forn d'obra. Aquest es troba en un estat parcial de conservació. (fotografia 6).

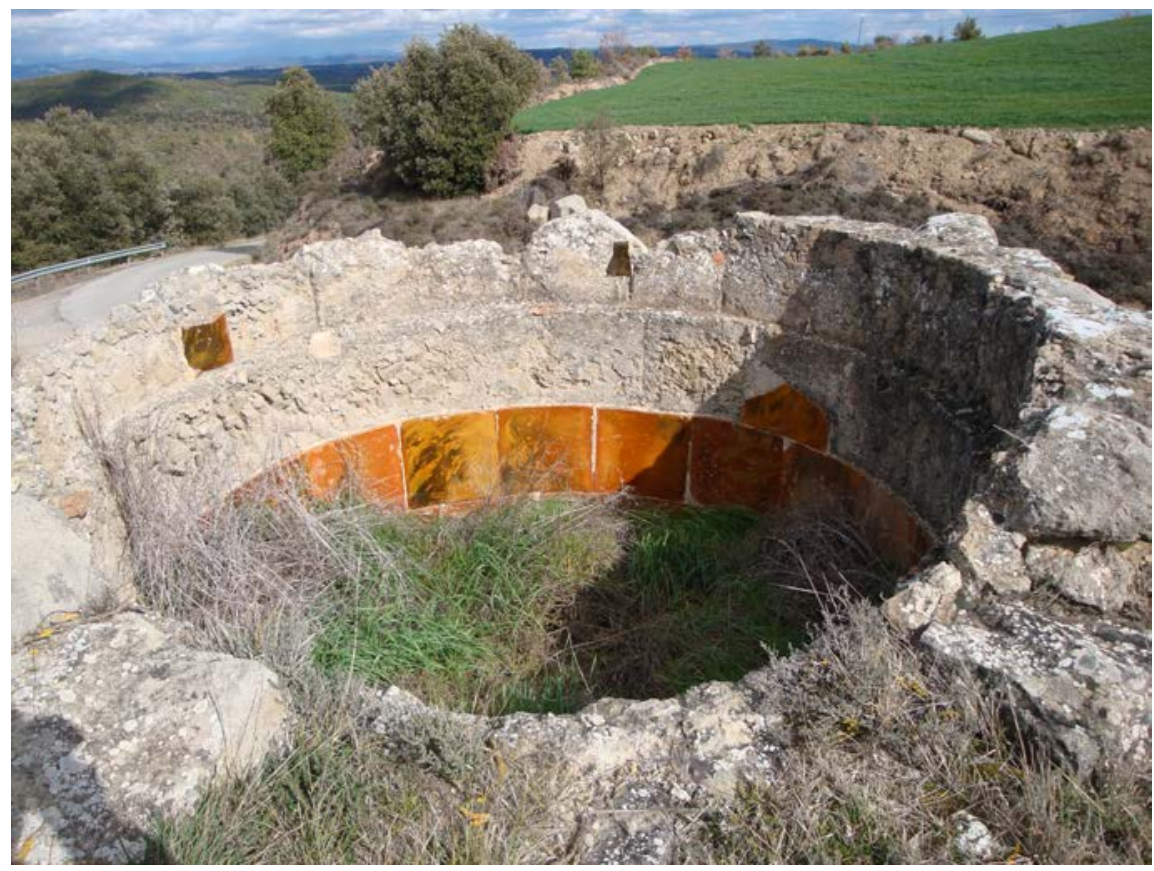

Fotografia 6. Part alta del Forn d’Obra de la carretera a Sant Joan de Montdarn

\subsection{Parada 7. Roc estret, carretera a Viver, (Sant Joan de Montdarn, terme municipal de Viver i Serrateix, comarca del Berguedà). (Full 330).}

Després de fer la parada anterior, cal continuar pel camí veïnal (carretera), que es dirigeix cap a Viver. Aviat, trobarem per la dreta la carretera que procedeix dels pobles de Montmajor i de Montclar. Poc després, arribarem a Sant Joan de Montdarn, des d'on ens caldrà seguir cap a Viver. A uns $5 \mathrm{Km}$ de la parada anterior i a poc més de $1 \mathrm{Km}$ de Sant Joan, efectuarem una nova aturada.

En aquest recorregut, hem anat trobant els materials esmentats a la parada anterior, els quals pertanyen a la Formació Solsona. Així, s'hauran fet palesos els nivells de calcolutites de tonalitats ocres i els gresos.

Tot i així, en arribar a aquest indret, s'haurà fer patent l'increment dels materials detrítics. Així, ens haurem trobat per sobre de la carretera un important nivells de conglomerats i de gresos. És el podríem denominal nivell de conglomerats de Viver Aquest nivell el tenim ara per sobre 
de la carretera, constituint els nivells més alts del voltants de San Cugat de Montdarn i també de Viver. (fotografia 7).

Per d'altra banda, ara estem circulant per un nivell similar a l'anterior, i es poden observar molts bons exemples de relleu ruïniforme, a partir dels blocs disgregats (fotografia 8).

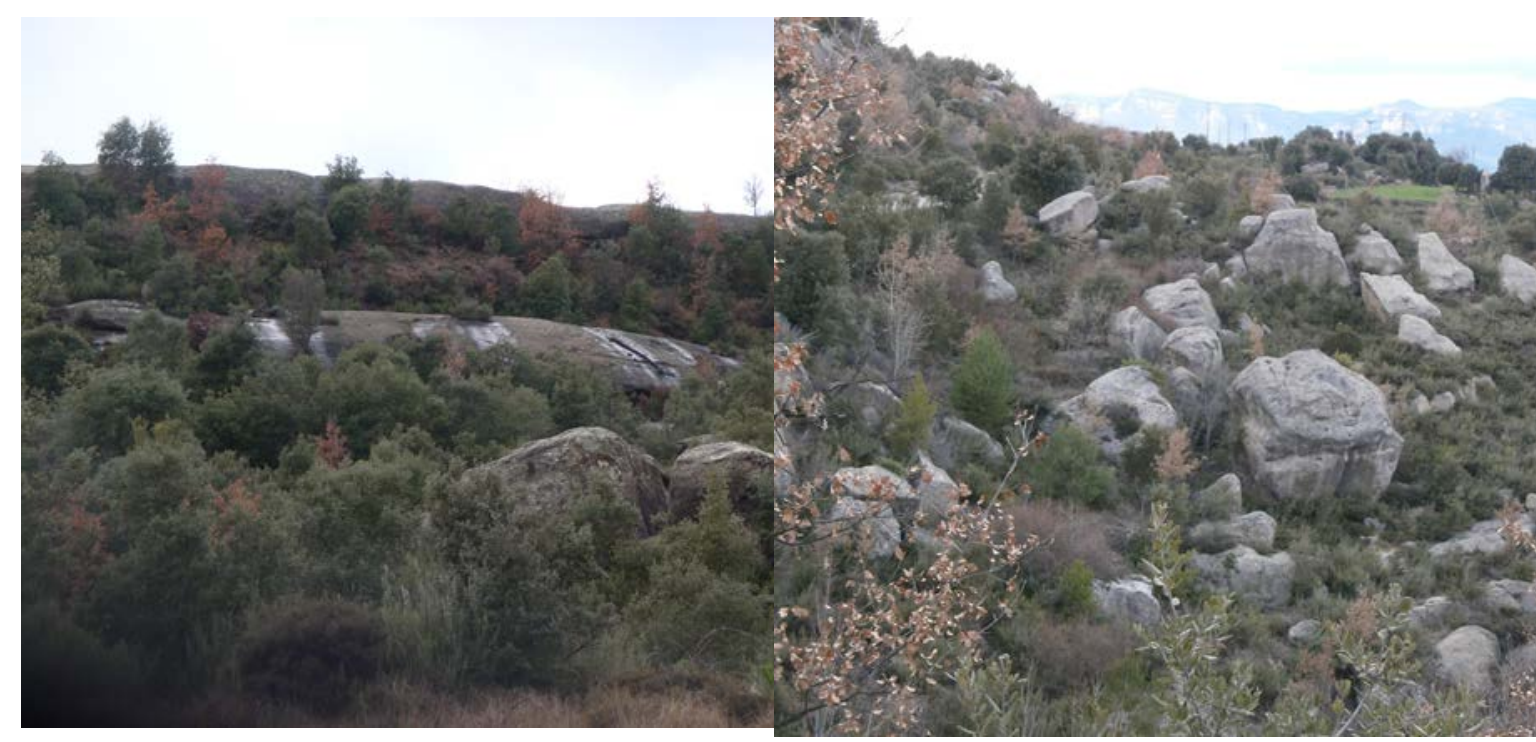

Fotografia . Nivells detrítics de Sant Joan de Montdarn i de Viver
Fotografia 8. Relleus ruïniformes, prop de Sant Joan de Montdarn

\subsection{Parada 8. Els Castellots, (Viver, terme municipal de Viver i Serrateix, comarca del Berguedà). (Full 330).}

Després de fer la parada anterior, cal continuar cap a Viver, per la carretera veïnal que hem agafat a Casserres. Així, ara, en uns $4 \mathrm{Km}$ arribarem al primer poble esmentat. En arribar-hi, ens caldrà anar cap a ponent, cap a la Serra de la Vila. En arribar-hi, farem una nova aturada, a uns $5{ }^{\prime} 5 \mathrm{Km}$ de l'anterior. Així, haurem arribat al paratge dels Castellots.

També, hi ha la possibilitat de seguir per la carretera que es dirigeix cap a Serrateix, la BV4235. Seguint per aquesta carretera, podem fer una aturada a poc més de $1 \mathrm{Km}$ de Viver. Així, també haurem arribat als Castellots, a uns altres de similars.

En qualsevol cas, haurem circulat entre els afloraments dels materials de la Formació Solsona i haurem trobat afloraments dels nivells de calcolutites ocres i dels gresos, que pertanyen a I'Oligocè.

Una mica més amunt (en els dos casos), haurem trobat uns afloraments de nivells més detrítics, concretament dels que hem dominat a la parada anterior com: conglomerats de Viver. Aquests materials són els que constitueixen els Castellots. Es tracta d'un relleus prominents, entre els que s'observen molts tafònits. (fotografia 9). 


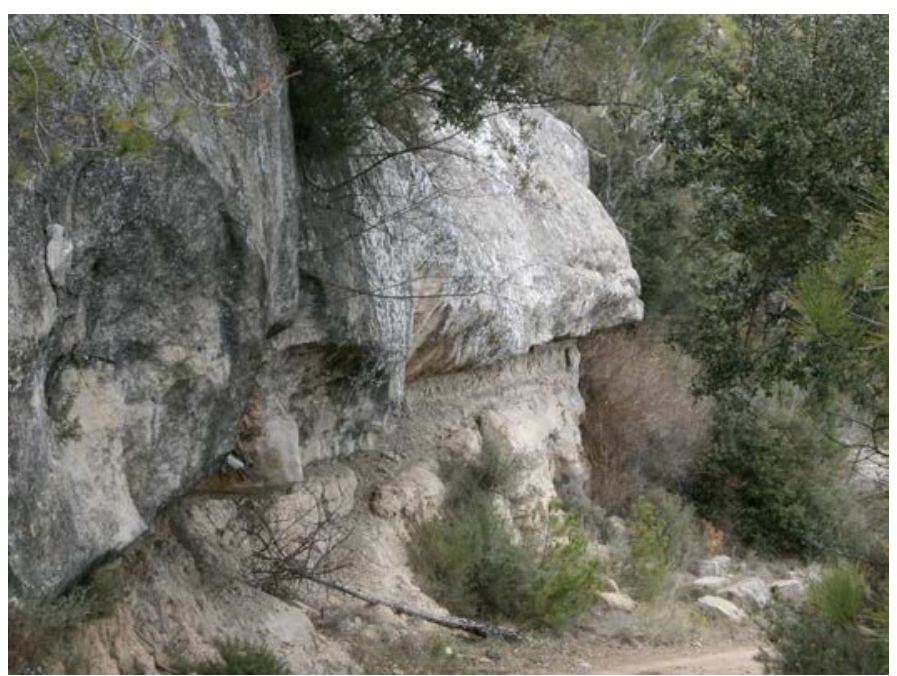

Fotografia 9. Aflorament dels conglomerats de Viver, al Serrat de la Vila, per sobre de Viver

\subsection{Parada 9 - Condicional. El Roc de Sant Urbici, (Serrateix, terme municipal de Viver i Serrateix, comarca del Berguedà). (Full 330).}

Després d'efectuar la darrera aturada, cal continuar per la carretera local BV - 4235, per tal d'anar cap el poble de Serrateix. En arribar-hi, cal anar cap l'indret on hi ha el Càmping. Prop d'ell, al seu nord, farem una nova aturada. Així, des de l'anterior, haurem recorregut uns $5 \mathrm{Km}$ més, aproximadament.

En aquest recorregut, hem tornat a trobar afloraments dels materials esmentats a les aturades anteriors. Així, hem trobat afloraments dels materials de la Formació Solsona i també dels que hem anomenat Conglomerats de Viver.

Precisament, en aquest indret hi ha un fragment d'aquest darrer nivell, que s'ha mantingut aïllat a l'erosió, individualitzat. És conegut a la zona com a "Roc de Sant Urbici". (fotografia 10).

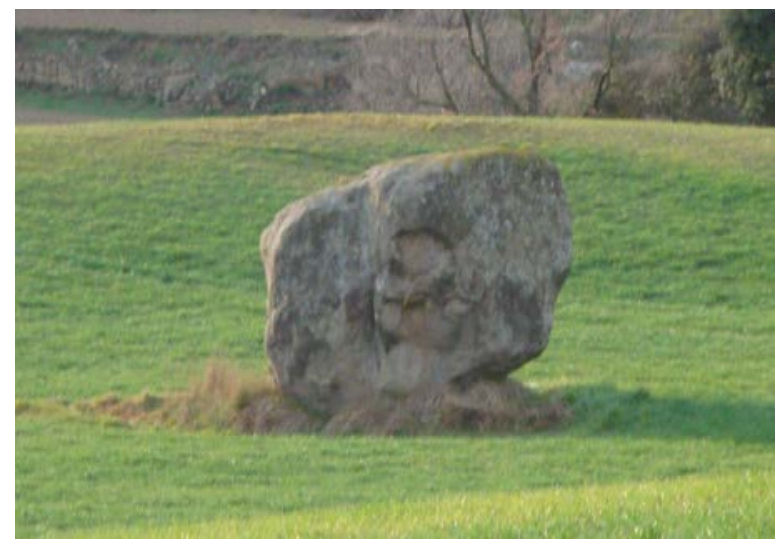

Fotografia 10. Roc de Sant Urbici, Serrateix 


\subsection{Parada 10. Immediacions de la cruïlla de Castelladral, (Castelladral, terme municipal de Navàs, comarca del Bages). (Full 330).}

Després de fer l'aturada anterior, cal sortir cap el Sud, per la carretera local (en realitat pel camí veïnal) que condueix cap el poble de Castelladral. En arribar podem fer una nova aturada, després de passar de la comarca del Berguedà a la comarca del Bages. Així, haurem efectuat un recorregut proper als 6' $5 \mathrm{Km}$. En arribar-hi, farem una nova aturada.

En aquest recorregut, entre Serrateix i Castelladral, hem anat trobant inicialment els materials esmentats a les aturades anteriors. Així, hem vist afloraments de les calcolutites ocres i dels gresos que constitueixen la Formació Solsona. Tot així, poc a poc hem començat a trobar nivells rogencs de calcolutites i gresos que pertanyen a la Formació Artés. Aquests són els materials que apareixen a l'indret de la present aturada. Tot i així sovint hem trobat paleocanals entre els materials anteriors, $d$ 'ambdues formacions.

Des d'aquest indret, es pot gaudir d'un bon lloc d'observació, d'aquests sectors de la Depressió Geològica de l'Ebre, on ara ens trobem. Així, mirant cap el Sud es poden veure els relleus de Montserrat (fotografia 11). I tanmateix, mirant cap el SSE, es poden veure els relleus de Sant Llorenç de Morunys i Serra de l'Obac (fotografia 12). En aquest cas, fins i tot es pot veure la silueta del Montseny, de la Serralada Prelitoral. En ambdós casos, es poden veure els relleus de la Depressió Geològica de l'Ebre, pels voltants de Sallent, Santpedor, Navàs, Súria, per sota d'on ara som.

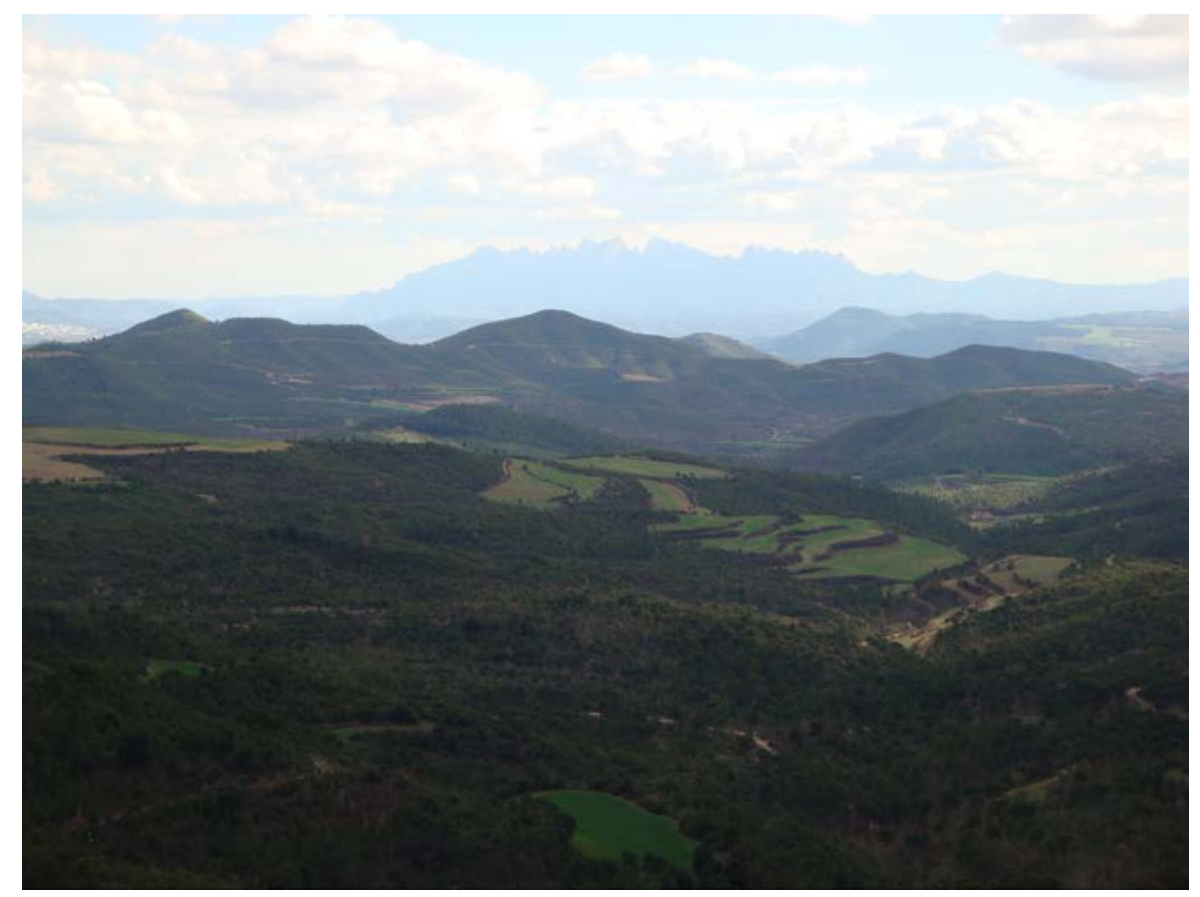

Fotografia 11. La Depressió Geològica de I’Ebre, al Sud de Castelladral, amb Montserrat al fons 


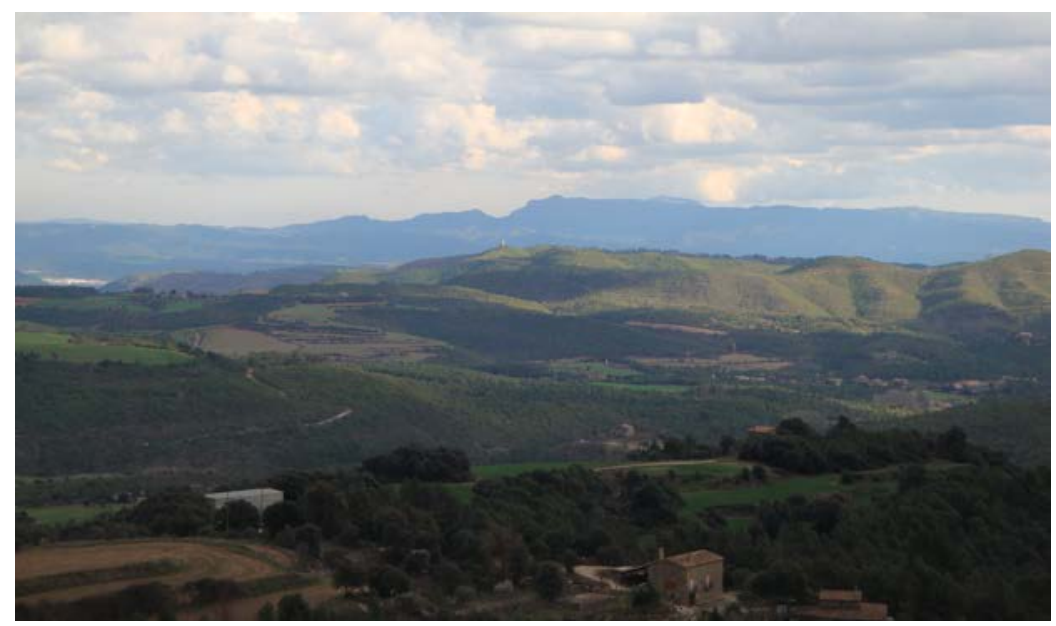

Fotografia 12. La Depressió Geològica de l'Ebre, al SSE de Castelladral, amb Sant Llorenç del Munt i Serra de l'Obac al fons. A l'extrem més oriental s'entreveu la punteta del Montseny

\subsection{Parada 11. Collet de Cal Siló, (terme municipal de Súria, comarca del Bages). (Full 330).}

Després de fer la parada anterior, cal continuar cap el Sud, seguint ara per la carretera local B - 423, tot anant cap a la població de Súria. En arribar a les immediacions del Km 2, farem una nova aturada, a uns $7 ` 5 \mathrm{Km}$ des de la parada anterior.

En aquest recorregut, hem anat trobant els materials continentals rogencs, de la Formació Artés. Aquets materials es troben constituïts per trams de calcolutites rogenques, alternant amb gresos. Molt sovint, hem trobat paleocanals, entre aquests materials.

Cal dir que aquests materials presenten generalment un clar cabussament cap el Nord. Aquests materials es van inclinant més cap els Km 3 i 4 . Tot i així, cap a les immediacions d'on ara som, es comencen a inclinar cal el Sud. Això és conseqüència de l'Anticlinal de la Falla de Mig Món. (fotografies 13 i 14).

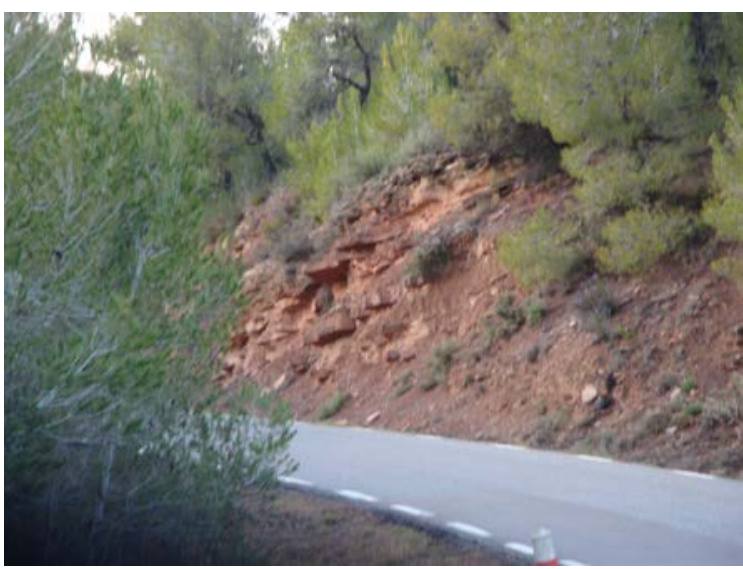

Fotografia 13. Materials de la Formació Artés, inclinats cap el Nord, al Km 2’8

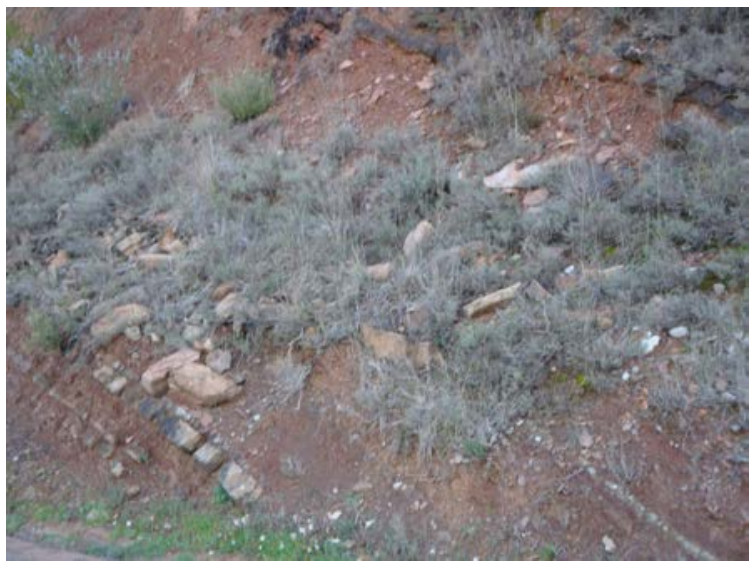

Fotografia 14. Materials de la Formació Artés, inclinats cap el Sud, al Km 2 ' 


\subsection{Parada 12. Mines de de potassa de Súria, (terme municipal de Súria, comarca del Bages). (Full 330).}

Després de realitzar l'aturada anterior, cal fer un nou recorregut cap al Sud, anant cap a Súria. Així, a poc menys de $1 \mathrm{Km}$ de l'anterior aturada, en podem realitzar una altra, a menys de 1 $\mathrm{Km}$ de la població de Súria.

En aquest recorregut, hem continuat trobant afloraments dels materials rogencs de la Formació Artés, que ja hem trobat als recorreguts cap a les parades anteriors. Així, hem vist afloraments de calcolutites rogenques (sovint molt argiloses), alternant amb nivells de gresos, sovint també rogencs. Per d'altra banda, cal dir que aquests materials forment par del flanc meridional de I’Anticlinal de la Falla del Mig Món de Súria.

Des d'aquest indret on som ara, mirant cap a ponent, es poden veure els formosos castellets miners, del Pou 2 i del Pou 3, de les mines de Súria, de l'empresa Iberpotash. fotografia 15.

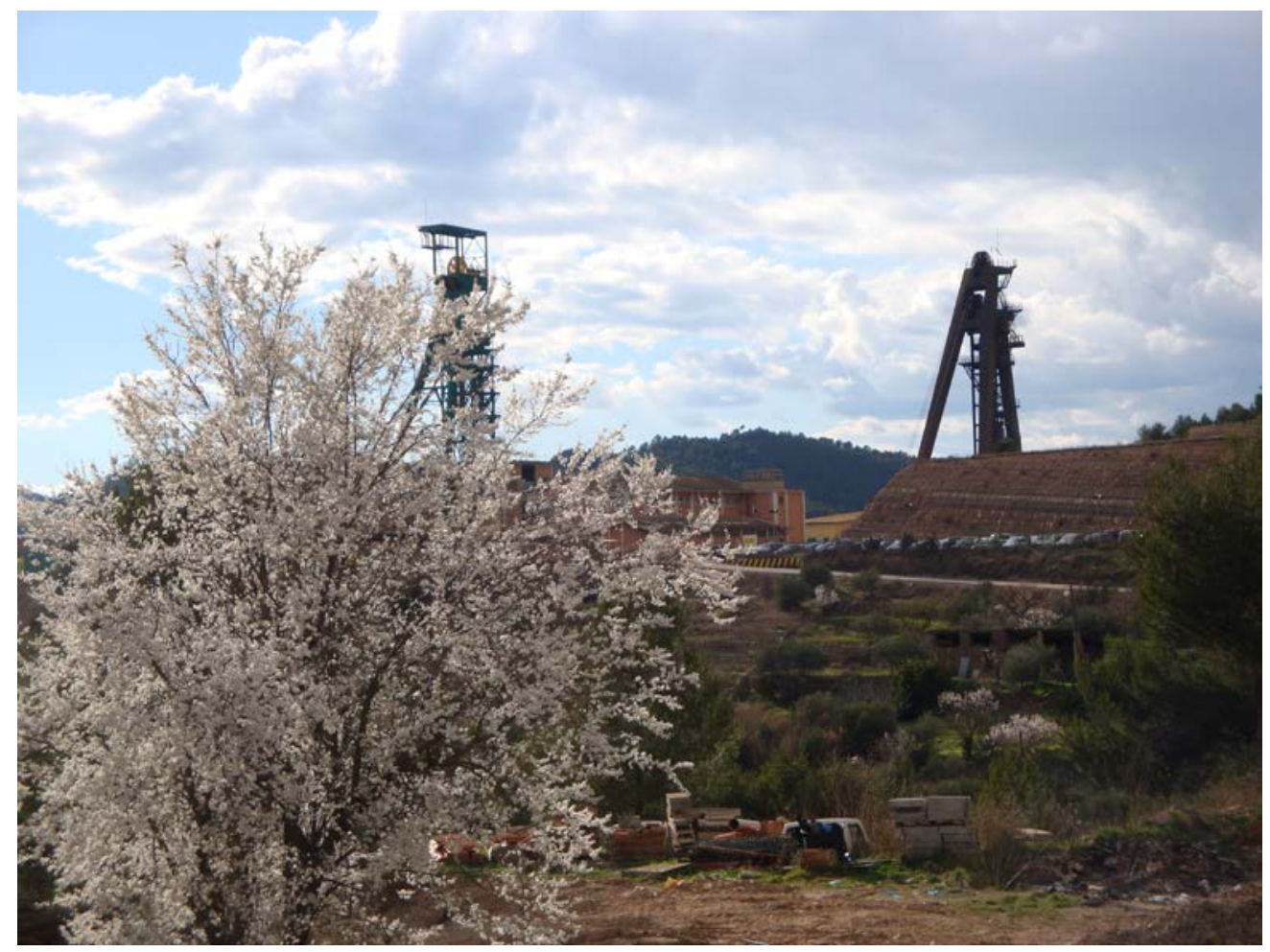

Fotografia 15. Els castellets del Pou 2 i del Pou 4, de les Mines de Súria d’IBERPOTASH, a Súria

En aquest indret finalitza el recorregut de l'itinerari. 


\section{Bibliografia}

GUIMERÀ, J. et altri (1992).- Geologia (II), Història Natural dels Països Catalans, Vol. 2, 547 pag. Enciclopèdia Catalana, S.A. Barcelona.

IGME (1994a).- Explicació del Mapa Geologico de España, a escala 1:50.000 (full 293, Berga Pobla de Lillet). Inst. Tecnol. y GeoMinero de España. Minist. Indústria. Madrid.

IGME (1994b).- Explicació del Mapa Geologico de España, a escala 1:50.000 (full 330, Solsona). Inst. Tecnol- y GeoMinero de España. Minist. Indústria. Madrid.

MATA-PERELLÓ, J. M. (1984).- Els minerals del Berguedà. revista Xaragall, nº 3, 38 pag. Manresa.

MATA-PERELLÓ, J. M. (1991).- Els Minerals de Catalunya. Arxius de la Secció de Ciències de I'Institut d'estudis Catalans, vol.47, 545 pàgines. Barcelona.

MATA-PERELLÓ, J. M. (2006).- Recorregut de recerca geoambiental per les comarques del Bages i del Berguedà: des de Santpedor i Castellnou de Bages a Súria, Castelladral i Serrateix. Inèdit. 12 pàgines. Manresa

MATA-PERELLÓ, J.M. i SANZ BALAGUÉ, J. (1991).- Guia de determinació dels minerals. Països Catalans i Altres. Edic. Parcir. Manresa.

RIBA ARDERIU, O. et altri (1976).- Geografia Física dels Països Catalans. Edit Ketres. Barcelona 